\title{
Implementing a new mathematics curriculum in England: district Research Lesson Study as a driver for student learning, teacher learning and professional dialogue.
}

\section{$\underline{\text { Author list and affiliations }}$}

Peter Dudley $^{1 *}$, Paul Warwick ${ }^{1}$, Maria Vrikki ${ }^{1}$, Jan D. Vermunt ${ }^{1}$, Neil Mercer ${ }^{1}$, Nicolette van Halem², Anne Mette Færøyvik Karlsen ${ }^{3}$

\footnotetext{
${ }^{1}$ Faculty of Education, University of Cambridge UK; 184 Hills Road, Cambridge, CB2 8PQ; +441223 767600

${ }^{2}$ Faculty of Social and Behavioural Sciences, University of Utrecht, PO Box 80125, 3508 TC Utrecht, The Netherlands

${ }^{3}$ University of Stavanger, Norway; Kjell Arholmsgate 41, 4036 Stavanger, Norway; +47 51831000

* Corresponding author: Peter Dudley - pjd45@cam.ac.uk
}

\begin{abstract}
Against a backdrop of a transformation in teacher professional development and learning and state school organisation in England this century, this chapter describes a project which harnessed six cycles of Research Lesson Study at school and district level over two years to tailor the implementation of a new statutory curriculum in England to address the professional development needs of teachers and classroom learning needs of London students. It also reports the findings of research carried out during the project into how these teachers learned and developed this new curricular expertise and practiceknowledge through lesson study dialogues that supported student learning. It concludes by proposing future directions for teacher professional learning research and practice.
\end{abstract}

Keywords: lesson study; school-collaboration; dialogue; teacher learning.

\section{Introduction}

This chapter introduces a popular form of Lesson Study (LS) in the UK and reports on its use in supporting 96 primary and secondary schools in London as they reviewed and re-wrote their mathematics curricula in order to improve the mathematics learning of their students. The background context to this work was the lead-up to changes made to the statutory mathematics curriculum in England (DfE, 2013).

In the first section, we will set the scene by placing this development in teacher learning in the context of transformational changes in teacher professional development that have taken place 
over the past 25 years in England. We will then focus on the model of 'Research Lesson Study' used in the project. We will describe the features it incorporated of both Japanese Lesson Study (JLS) and District Level Lesson Study into a deliberate, interleaved process and focus on two particular RLS elements 'case pupils' and 'pupil interviews' - that helped to promote the modes of teacher learning that we discuss in depth in section 3.

The second section will describe the context of the two year Camden ${ }^{1}$ New Curriculum Mathematics Lesson Study Development and Research Project: its aims, scale and methods. It will present evidence from the project evaluation, of impact on teachers' development of pedagogical content knowledge in areas of mathematics that they had identified as being the hardest to teach and the hardest for pupils to learn. It will also present evidence of the impact this work had on pupil learning in the new curricula that were developed.

The third section focuses on research undertaken as part of the Camden project into the mechanisms of teacher learning within LS planning and reflection discussions. It examines: the forms of interaction that were productive for teacher learning; the nature of teacher learning processes in these discussions, and their relationship to dialogue moves by teachers; the learning patterns evident as the teachers engaged in these discussions over time, and their relationship to ideas about teacher identity; and in addition, the ways in which teachers incorporated pupil voice into their discussions.

The fourth and concluding section will briefly look ahead to the next steps for practice and research.

\section{A background to the development and adoption of Lesson Study in the UK}

\section{A prelude to the late $20^{\text {th }}$ century 'Neo-liberal' reforms}

Figures such as Lawrence Stenhouse and John Elliot positioned 'critical' teacher development and agency alongside classroom action research as essential components of successful curriculum development and sustainable improvement of classroom learning (Stenhouse,1981; Elliott, 1991). However, in reality typical experiences of teachers of later $20^{\text {th }}$ century 'In Service Education and Training' (INSET ${ }^{2}$ ) in the UK, were highly variable, and determined by

\footnotetext{
${ }^{1}$ A municipality and school district in central London.

${ }^{2}$ INSET is used here to distinguish 'in service' teacher education from 'pre-service'.
} 
the degree to which the school (or local authority in which the school was located) valued, promoted and funded such activity.

The introduction of the English National Curriculum and its statutory national assessment processes in the early 1990s witnessed an explosion of in-service teacher training. The government wrote five days school closure for INSET into law in 1988. State schools became quasi-independent businesses. They were regulated by a national inspectorate, 'Ofsted'3; ranked annually by public examination results and by inspection ratings. Teachers were also subject to annual statutory lesson-observation based performance-management.

A revolution in INSET followed as schools quickly realised that if they were to gain the positive inspections grades and test rankings they needed to attract pupils and funding, then they were going to need good results.

\section{Lone practice and centre based professional development}

Despite the curriculum, over half of English 11 year olds 'failed' the first national tests in 1995. The 1997 Blair government responded with the 'National Strategies' (NS) (Department for Education and Skills, 2007.) aiming to increase attainment through a focus on core curriculum subjects with training from 450 local authority-based consultants and 900 school-based 'leading teachers'.

'Yet despite evidence that learning is 'situated' (Lave and Wenger, 1991; Scribner, 1999; Puttnam and Borko, 2000), taking place most effectively in the context where what is learned is practised, most of this training continued to take place away from classrooms and students.

\section{Harnessing teacher agency and classroom led reform}

An independent review of NS by the Ontario Institute of Studies in Education found that while initial gains had been impressive, continued top-down delivery of centralised policies was diminishing returns, and risked de-professionalising teachers' (Earl, et al. (2003). It recommended encouraging 'disciplined-innovation' (Hargreaves, 1999) of improvement in schools, led by practitioners.

\footnotetext{
${ }^{3}$ Oftsed is the abbreviation of 'Office for Standards in Education' England's national schools inspectorate.
} 
The door was opened for LS in England.

\section{The introduction of Research Lesson Study}

First piloted from 2003-5, it was 2008 before Research Lesson Study (RLS - See Fig 2 below) found its way into mainstream policy (Dudley, 2005, 2008). In 2008 - 2009 teachers of 11 year olds in half England's underperforming, 'coasting' primary schools were supported by NS 'Leading Teachers' using RLS to develop pedagogical content knowledge and practiceknowledge in literacy and mathematics. In both years, national test result improvements for the RLS supported schools were double those of the other schools supported through traditional approaches, and higher still than the national increases (Hadfield, Jopling \& Emira, 20114).

Evidence was also mounting that teacher learning that best improves pupil learning takes place over time and involves in-class experimental collaboration by teachers (Cordingley et al. 2004; James et al, (2007) but less than 2\% of teachers in England reported regularly experiencing such opportunities (Opfer and Pedder, 2010). Robinson's (2009) meta-study (and more recently John Hattie (2017) reconfirmed) that leading systematic school-wide enquiry by teachers into how to improve learning (not teaching) had the single greatest impact on student attainment of all the actions at a principal's.

Austerity and the renaissance of teacher and schools-led development

During the post 2010 years of austerity, large scale, government sponsored Continuing Professional Development (CPD) ceased in England. Schools were a encouraged to develop enquiry informed, self-improvement processes (McKinsey 2007; DfE 2010; Mourshed, et al. 2010.) along the lines originally proposed by Earl et al. (2003) (See section 1.iii). Four hundred 'Teaching Schools' were funded to support such activity locally. 'Teachers as researchers' blossomed in the form of social media groups actively encouraged by a national policy environment promoting innovation, enterprise and competition.

\footnotetext{
${ }^{4}$ The RLS model has been subject to two further large scale trials of 800 schools and 280 schools respectively (DfE NCTL, 2016; Education Endowment Fund, 2017) demonstrating improvements in pupil outcomes and receiving positive reactions from professionals in both. While neither trial showed an overall effect size, the improvements in the 2016 study led to a recommendation that RLS be considered as one of only two interventions by schools for narrowing attainment gaps.
} 
Lesson Study thrived as schools, and local school partnerships developed their own in-school enquiry approaches to professional learning. By 2012 it was estimated that up to $10 \%$ of English schools had used Lesson Study (Dudley, 2012).

\section{The New Mathematics Curriculum development Lesson Study Project}

Around this point in the development of LS in England, the Greater London Authority (GLA) funded the London Borough of Camden in partnership with the University of Cambridge, to run a two year development and research programme (2013-15) to study how 96 London schools used a design-based, district level lesson study approach to develop and implement the new mathematics national curriculum. The new curriculum was intended to raise standards in mathematics at 11 and 16. This project concentrated efforts on students aged 10-13 years completing their primary schooling and commencing secondary education. The new curriculum expected 11 year olds to be competent in mathematics that had previously been expected of 12.5 year olds. Teachers in the project were encouraged to concentrate on areas of the new curriculum they believed would be hardest for them to teach and students to learn. The

key areas of mathematics in which at least a quarter of the teachers identified that they had little or no confidence included:

- Place value for decimal notation of fractions

- Written methods of division involving decimals

- Finding $100 \%$ given a percentage part

- Algebraic distinctions and terminology, providing explanations and solving simultaneous equations algebraically

- Identifying formulae, and models for algebraic equations, direct proportion and graphical representations

- Explaining the distinctions between types of numbers and illustrating particular forms of number

- Calculations involving fractions

- Dividing a quantity in a given ratio.

(Source: Bufton, N. Analysis of teacher confidence survey, New Curriculum Mathematics LS project, 2013.)

How LS helps teachers learn mathematics pedagogical content and practice knowledge 
Part of this project focused on investigating how modes of teacher learning in lesson study identified by Vermunt (2011) and Dudley (2013) operate at scale, and how they might be modified to improve the learning of teachers in ways that improve the mathematical learning of pupils.

Inspired by Japanese processes of curriculum renewal such as those described by Kuno (2015) the project attempted to create a means for primary and secondary schools to reflect on the kinds of mathematicians they wished to develop, the means by which this might be achieved, and the curriculum and pedagogical approaches that might best achieve these outcomes. In the next sections we consider the RLS model in comparison with others, and further adaptations made for the Camden project.

The model of Lesson study used for the programme

Different models of lesson study exist in Japan, but most models used outside Japan include the following components (Takahashi and McDougal, 2016): (a) curriculum study (progression before and after the unit); (b) lesson design (critical features of the lesson or unit design and what we can learn from it); (c) school theme (progress related to the school's research theme) and (d) next steps for future teaching. They also summarised principles contributing to effective Japanese lesson study stating that: its purpose is to collaboratively build expertise (not perfect lessons); it is part of a highly structured, school-wide, even district-wide process; it includes significant curriculum review, student and progression study (kyouzai kenkyuu); it takes weeks (not hours); and planning and post lesson discussions are supported by 'knowledgeable other' experts.

Catherine Lewis (2016) has reported on the different forms of professional learning and development that tend to take place at each of the stages Takahashi identifies. 


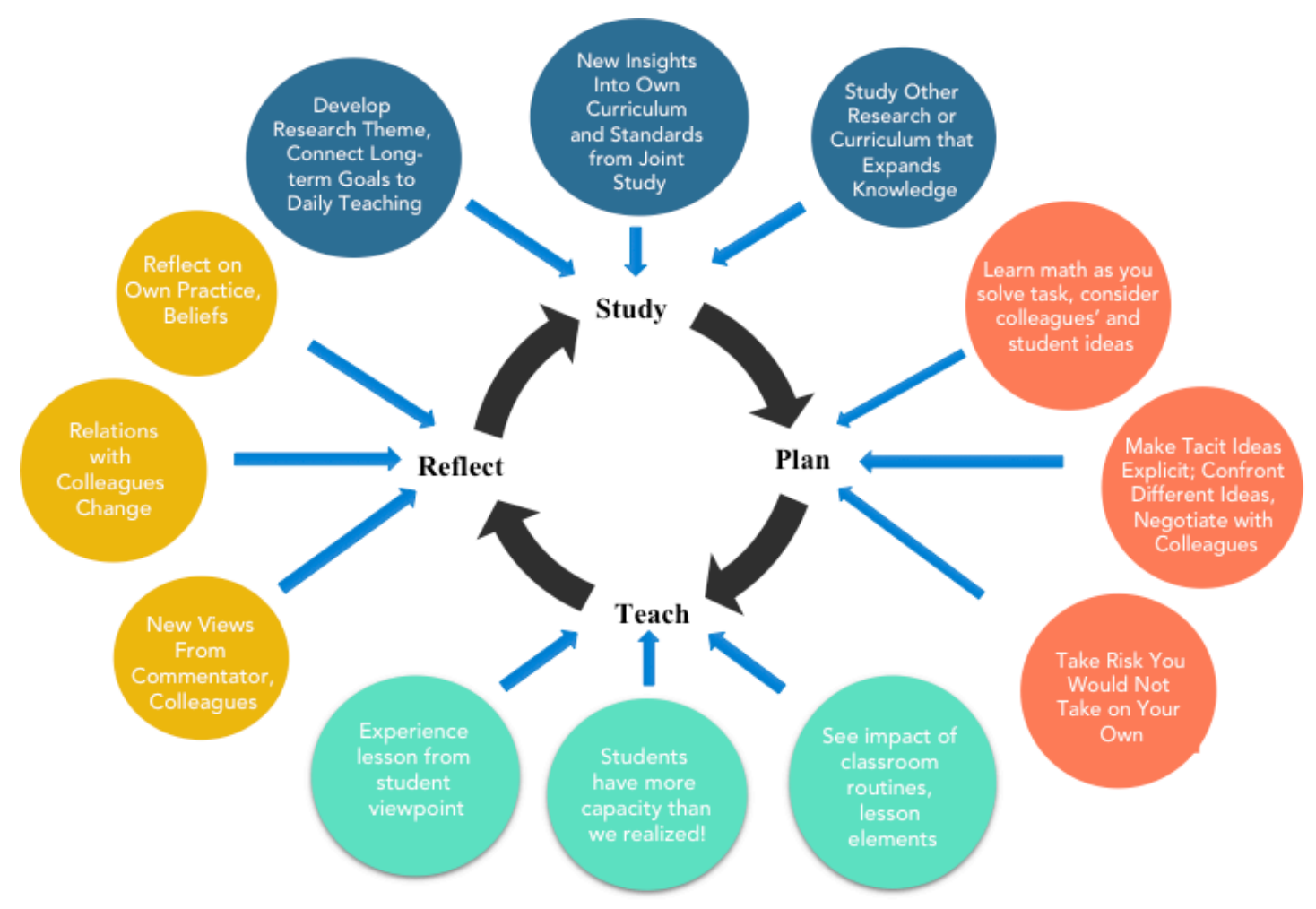

Figure 1. What learning occurs at each stage of the Lesson Study Cycle. 단, Lewis, C. (2016) Reproduced with kind permission.

How RLS differs from other forms and why this happened

Research Lesson Study (RLS) was first developed in England in a national pilot (Dudley, 2005, 2011, 2015) (See Figure 2 below). We will briefly explain the rationale for and genesis of the development of its key distinguishing features: three research lessons, case students, student interviews and a focus on dialogic learning.

\section{A note on learning theoretical underpinnings of $R L S$}

When RLS was first piloted in 2003 the literature on LS English was in its infancy. Little was knowledge about Chinese Lesson Study. The dominant models were Japanese LS and its US implementation, which was mainly in mathematics education (Lewis, C. 1998; Fernandez, C et al. 2003; Yoshida, M. 2002). The national pilot developed LS in a range of curriculum areas (Dudley, 2012). It was also developed with teachers who had not experienced LS's ability to help them to see their students' learning with new eyes or to access their tacit stores of practiceknwowledge (Dudley 2013, Dudley 2015). Teachers in England were also deeply wary of situations where another teacher was with them in their classroom as a result of lone practice 
and of the tyranny of Ofsted inspection and performance management processes that discouraged risk-taking or any disclosure of professional need (Dudley, 2015). The emphasis in the 2002-5 pilot was on developing safe spaces in which teachers learned not only about improving their student's learning, but also: how they themselves can learn collaboratively with fellow teachers; that it is acceptable not to know everything (nobody does!); that it is both rewarding and a professional imperative to develop practice-knowledge together and to pass it on to others. For these reasons, post lesson discussions were also conducted iteratively' within the three research lesson (RL) cycle before what was learned was made public and open to critique of commentators and peers.

The overall theoretical underpinning for both teacher and student learning in RLS is broadly sociocultural drawing on Vygotskian principles. However, in the 'study phase' teachers are also encouraged to draw upon strongly evidenced curricular and pedagogical approaches and innovations in subject teaching, and to use RLS to incorporate these into their classrooms. With the benefit of increased LS literature and the work of organisations such as the World Association of Lesson Studies it is now clear that there are strong parallels between UK RLS and Chinese Lesson Study. One other LS form used less widely in the UK is Learning Study. Learning Study developed in Hong Kong and Sweden combining Chinese and Japanese LS approaches with Marton's 'variation' theory of learning (Lo M.L. 2016). It's use in the UK is most common in schools for children with learning difficulties and difficulties. It was not used in this project.

Why three research lessons?

Lewis's 'study' phase (Figure 1), during which teachers review their existing practices and research alternatives is carried out before lesson planning or teaching begin. However, in RLS the 'study' phase is revisited between the three research lessons. This is because when the RLS model was first co-evolved with teachers (2003-5), teachers in England found it helpful hypotheses over two or three cycles of review and planning. This is common in Chinese forms of LS. At this time teachers were not used to close observation of student learning - they were used to 'observing teaching'. This iterative 'design study approach' therefore afforded opportunities for 'reconnaissance' (Elliott, 1991) and tentative 'field testing' of hypotheses and also subsequent development in later research lessons (Dudley, 2013). 
Figure 2. Three Cycle Research Lesson Study model used in this project.

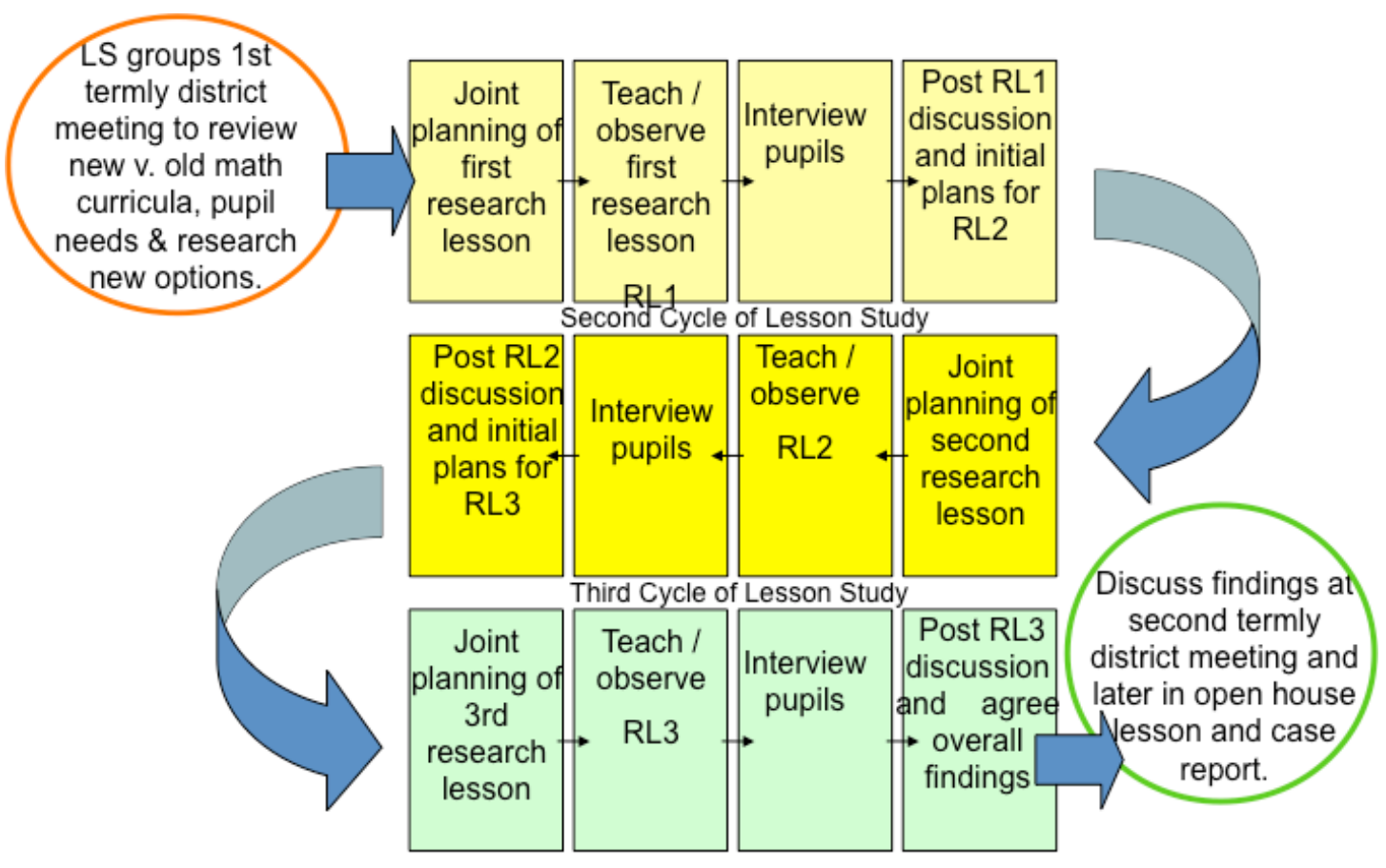

To develop this point, the first research lesson is often 'revelatory' reconnaissance for teachers. They discover, through close observation of learning, stark differences in what they had imagined to be true about their pupils as learners, and what they actually observed to be the case. As a result, assumptions made in the study phase need adjusting and testing out again in a second research lesson. Hypotheses developed in the initial study phase and refined as a result of the second research lesson, often need to be further adjusted or simply tested for replicability in the third.

The three-cycle model thus increases threefold the collaborative imagining and discussion of what might happen in a pre-lesson context, or what might have happened in a post-lesson context, influencing what teaching might be changed next time. Action and reflection processes are thus interleaved in this model. Dudley (2013) reports that such deliberate, interleaved processes are associated with the formation of close bonds of joint endeavour between LS group members. These help to create conditions of high intrinsic motivation (to help the students overcome identified barriers), high trust and high social capital. These not only enable teachers to take more risks (c.f. also Lewis, 2016 in Figure 1) but also enable them to access each others' normally invisible tacit knowledge. Accessing tacit knowledge of teaching and changing beliefs about practice (see Fig 2) are notoriously difficult to achieve (Eraut, 1994; Brown and McIntyre, 1993). The occurrence of these phenomena in RLS is most closely 
associated with discursive processes of (i) hypothesising (what might happen or might have happened) and (ii) 'rehearsing' hypothetical sections of the research lesson before and after it takes place, and doing so in role as teachers, using their 'teacher' voices to collectively conjure up the imaginary class before them (Dudley, 2013) as they 'interthink' (Mercer, 2000).

A further affordance of the three cycle RLS model is that it can be used to create two distinct forms of research lesson; either developing an object of learning (such as a skill) over a sequence of three different lessons with the same students; or the development and refinement of what is essentially the same lesson but with three different classes (a common feature of Chinese LS). The latter is more easily carried out in larger schools with three or more parallel classes (typically secondary schools (11-18) in England). The former is particularly attractive to smaller schools with only one or two parallel classes - the norm for primary schools.

There are two further distinguishing features of the RLS model: its use of 'case pupils' to help teachers focus on pupil learning in research lessons; and the use of pupil interviews to explore the pupils' own perceptions of their learning in these lessons.

\section{Case pupils.}

Collaborative dialogic learning is not only encouraged between teachers. It is used in RLS to promote student learning through exploratory talk (Barnes, 1971) and also so that by eavesdropping on this talk student thought processes and conceptions are made 'visible'. However, in order to see students clearly another strategy was incorporated into RLS.

In order to help teachers see the students in front of us (as opposed to the constructs of students we carry in our minds,) three or so case pupils are selected for specific attention during the RLS process. They are identified during the 'study phase'. In contexts such as that of this project where whole curriculum review and renewal is taking place, case pupils will often be typical members of learner groups in the class - perhaps one of those pupils who generally find mathematics easy and who are confident in mathematics; perhaps one from that group of learners who are less confident in mathematics, make slower progress and may require additional support. The third may be drawn from those between the two. At key points during the planning of the research lessons the lesson study group will imagine the learning that is to take place and predict what these case students are each likely to be doing, saying, drawing or writing if they are making the expected progress in the lesson and are ready to move on to the 
next stage. These predictions help set the agenda for the research lesson observers who check what they are actually doing, noting their observations down against the group's earlier predictions. Following the student interviews (see below), the post lesson discussion begins by discussing the actuals observed in comparison with the predictions. This process helps teacher observers to focus less on the teaching and more on the learning of the students throwing differences between predicted and actual pupil learning behaviours into sharp relief.

Post research lesson pupil interviews.

Immediately following the research lesson, a few students are interviewed by one or two members of the lesson study group. Case pupils may or may not be included. The aim of the interview is to discover the views and insights that the students themselves hold about their learning in the research lesson. Questions such as:

'If we were teaching this lesson again tomorrow to a class like yours, how could we change the lesson in to help them to learn more easily?'

Evidence from lesson studies using this approach (Dudley, P. 2012; Warwick 2018) suggest that students frequently have helpful insights (about what helped or hindered their learning and what aided understandings and 'lightbulb' moments) that no member of the LS group had imagined. It has proven to be a useful additional process for eliciting evidence of student learning and what students notice and value in teaching and lessons.

How Lewis's forms of learning map onto the RLS model.

The forms of learning identified by Lewis (2016) in Figure 1 above have been reported by Dudley as occurring in the RLS model $(2013,2015)$. It is notable however that there are differences between the stages at which these forms of learning fall in the RLS model. The RLS model evolved cycles of three RLs addressing a developing research focus as might be the focus of one cycle of the model outlined in JLS. School leaders will bring in expert facilitators to support groups where it is not available in school and where LS is networked in hubs, commentators will distil what has been learned further at district or hub sharing events. 
Figure 3. Forms of Learning in Research Lesson Study in the Camden New Mathematics Curriculum Lesson Study project. (Adapted from Lewis, C., (2016).

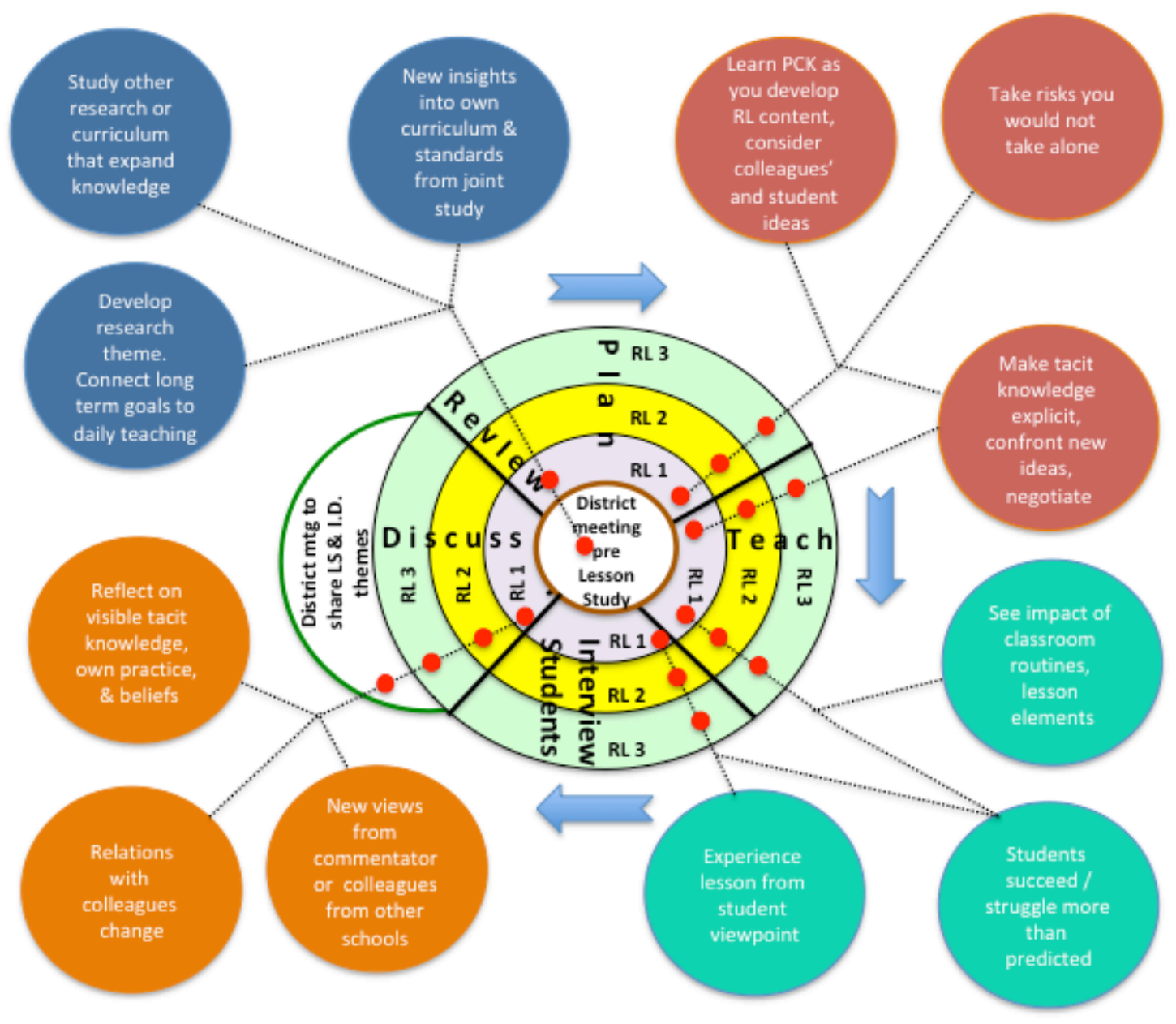

In Figure 3 above, the three consecutive research lessons are depicted as concentric circles each embodying elements of the review, plan, teach and reflect phases. The red dots show the recursive opportunities for teachers to test out and develop ideas, observe their effects on pupil learning and adjust the model. Lewis's forms of learning are mapped onto this depiction of RLS, using information about teacher learning in RLS reported by Dudley (2013).

Evidence from studies of RLS in England involving teachers 'interthinking' (Mercer 2000) (including those reported in this chapter), suggests that deliberate processes of collective review; hypothesising; imagining, predicting-and-observing student learning; and finally negotiating an agreed interpretation, affords LS groups opportunities to collectively solve teaching problems they could not have solved alone (Dudley, 2013). This mirrors processes of 
'interthinking' observed by Mercer (1995) amongst younger learners and later amongst studies of professional learners (Mercer 2014).

The recursive nature of the three research lesson cycle means LS group hypotheses can be reformed and tested out again. Usually, by the close of the overarching 'meta-discussion' drawing conclusions from all three research lessons, the LS group has developed practiceknowledge that they feel others would benefit from knowing as well.

At that stage the RLS model re-joins the JLS model set out in Table 1. Teachers share their newly discovered practice-knowledge with colleagues though open house lessons, presentations or case reports. There is evidence (Dudley 2013) suggesting that teachers who take this last step of passing on their knowledge are more likely to adopt and internalise into their own practice.

\section{The LS model used in this project}

The three cycle RLS model was further adapted for the Camden programme. Its use in the National Strategies (DfES, 2008, 2011) had involved subject expert teachers working with classroom teachers reviewing national mathematics and literacy materials and exploring through RLS how they might improve pupil learning. While the Camden RLS district approach contained these elements, there are certain differences. These were principally as follows:

- The core curriculum materials were the framework for the new national mathematics curriculum (Department for Education 2013) but the purpose of the project was to develop schemes of learning and core lessons to help schools to tailor the new curriculum requirements to the needs of their largely bilingual and in many cases (36\%) economically disadvantaged pupils.

- LS teams met with national experts in mathematics, curriculum development and knowledge-creation through lesson study twice each term to facilitate needs analysis, curriculum development and knowledge sharing across the schools (see Figure 5 below).

- LS teams conducted lesson studies that bridged the district-level knowledge creation with the needs of their own schools and also worked across the primary and secondary divide to build progression. 
The New Mathematics Curriculum LS Project used district LS planning and dissemination events to develop teacher mathematics pedagogic content and practice-knowledge and to improve pupil learning in those areas of mathematics that the teachers identified as hardest to teach and hardest (for students) to learn. Additional schools across London joined in the second year bringing the total involved to 96 . A considerable number have continued their district level work since the project ended. For the purposes of this chapter we will focus on the work of the 22 Camden primary, secondary and special schools that were involved for the full two years.

Figure 4. The timeline of the project

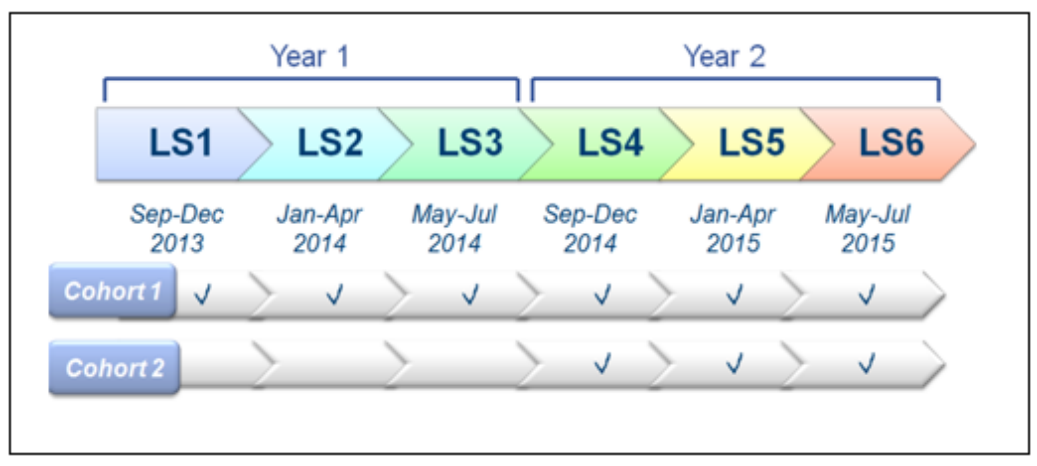

Two district level ( $1 \times 1$ day and $1 \times 0.5$ day) meetings attended by the LS groups from the. schools were held each term. The district support team provided expert input at these sessions on mathematics subject and pedagogical content knowledge; curriculum development and collaborative professional learning - with a focus on LS group dialogue. It comprised experts in: mathematics education, (including a national adviser and former Ofsted chief inspector), in teacher learning in lesson study (including, in the second year, a Chinese district lesson study leader/researcher) and (termly) the Cambridge University team (which included international experts in 'inter-thinking' and dialogic learning).

The first district meeting each term was to begin the 'study' phase collectively. Mathematics experts external and internal to the group worked with the teachers to elicit their conceptions of 'hard to learn' areas of mathematics, to probe their understandings of (and knowledge gaps in) how they might be more effectively learned. As well as this extended guided review and study phase, LS groups also began to scope their specific lesson studies, again exploring their ideas with the district level team. 
Following the teaching of the three-research lesson RLS cycle in schools, the LS groups and the district team met again for a five-hour second termly district meeting to share and reflect upon the findings from the research lessons. A final stage in the termly process involved members of the district team - including the Cambridge University research team - taking away the lesson study 'workbooks' (containing teachers' lesson study notes and data), as well as video recordings of the LS groups planning and evaluating their research lessons together. Cross-case examination of these data revealed themes that had not necessarily been evident at the sharing meeting. At the first event of the following term, prior to discussing the foci of that term's lesson studies, these common themes were presented by the research team and commentator and discussed amongst the school groups in order further to inform the lesson studies being planned for the coming term. These iteratively informed, district level meetings connected elements of the design cycle across groups of schools, helping to form common lines of enquiry and knowledge-building in these challenging to teach areas of mathematics. Figure 5 (below) illustrates how these common experiences developed into co-evolving enquiry themes as schools worked in similar areas sharing their findings with each other, enabling the development of information capable of use for curriculum development across school more broadly. 


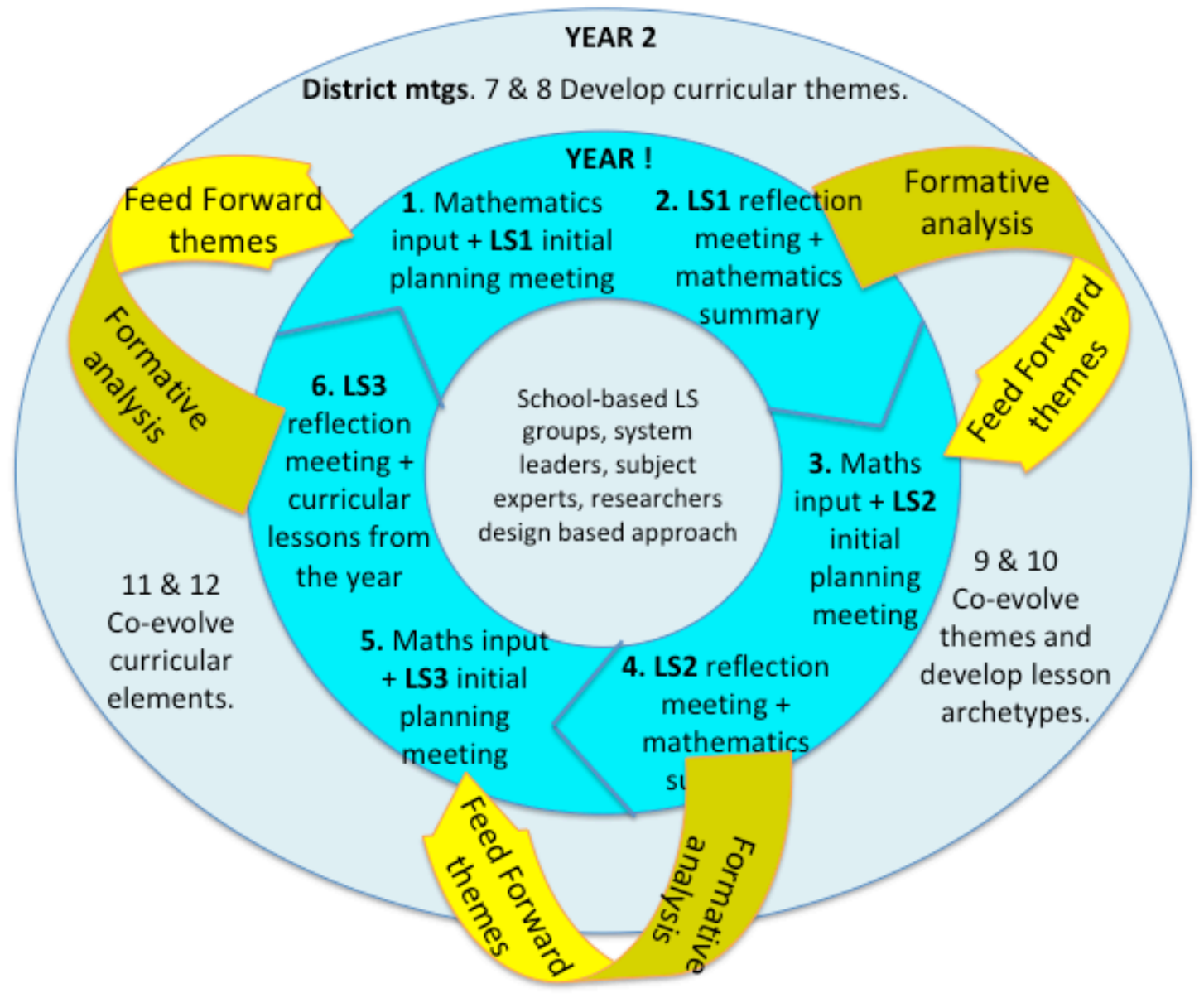

Each term, a number of schools held 'open house lessons' in which teachers and school leaders from across the whole borough were invited to participate, and where invited subject experts and commentators also shared their perspectives and advice on the lessons and curricula observed.

\section{Project development outcomes and learning outcomes}

132 research lessons were conducted by the 22 schools over the two-year period. All teachers in both primary and secondary schools reported greater confidence in teaching the "hard to teach and learn' areas of mathematics and also across the 22 areas of mathematics in the new curriculum in project surveys (Ylonen, Dudley and Lang (2015). Teachers also reported gains in pedagogical content knowledge, increased understanding of student misconceptions and knowledge of a far wider range of misconceptions than before. Schools developed their new 
mathematics curricula based on a shared understanding of what progression in the new primary and secondary curricula should 'look like' for their students, and frequently built around key lessons developed from the Lesson Studies

Evidence from almost $70 \%$ of lesson study workbooks revealed that by the end of the six terms, teachers were dedicating much more time than before to consolidating pupil learning and to strengthening recall and pupils' long-term memory of key information and underlying methods and procedures in mathematics. This was seen as important to secure recent mathematical learning before progressing to more challenging areas. Teacher comments included:

'We were struck by how important the pace of a lesson is...we noticed that we sometimes moved on too quickly or assumed understanding. This realisation tied in with our appreciation of the New Curriculum focus on mastery.'

'It is crucial that key concepts are secured and consolidated at each stage.'

'Real need to focus on basics, like place value, before you can move on to more complex areas, as without a solid base, everything else just gets lost. It is not wrong to go over these things again and again in a variety of different ways.'

The importance of language, vocabulary and verbalisation in mathematics teaching and learning was highlighted in over a third of the workbooks. Such structured use of talk enabled students to give their reasoning voice - and being able to express what they already knew helped students themselves to identify areas in which they were less secure.

'We have found that the children value the opportunity to talk and discuss what they are learning, including the strategies they are using... having the opportunity to talk through their understanding and reasoning.'

The use of 'talk partners' (a pedagogical technique supporting focused discussions between pairs of pupils) was highlighted in 40 per cent of the LS workbooks - not only for strengthening students' understanding but also teachers' ability to understand how their students understood the mathematics.

Sharing pedagogical approaches supported teachers to access practices developed in other lesson studies that they subsequently applied to their own teaching. Examples included:

- Ways of scaffolding the language of reasoning for children so that they more accurately express their ideas, give explanations and reasons. 
- Greater teacher awareness of the crucial importance of checking students' development of conceptual understanding and reasoning that leads to deeper learning and a greater repertoire of such concept checks. Early lesson studies revealed that it was common for children to be able to 'carry out' mathematical processes, but without understanding why the process worked.

- Children needed sufficient time to talk about the mathematics with peers during the learning processes.

- Many schools had not previously had a longer-term, strategic view of planning of mathematics.

- It was more useful for teachers to share examples of what can be achieved and processes for how to get there, than simply identifying good and bad practices.

The most profound learning, echoed by all involved, was the need to slow down initial concept introduction and to ensure students had thoroughly grounded their understanding for application. This led to the catch-phrase 'Go slow and grow'. Some schools used their research lessons as archetypal components of the new curricula they developed serving as reference points on the curricular landscape, for example, for inducting new teachers.

\section{Differences in attainment for the pupils in the project schools.}

Pupils attainment in the new National Curriculum for Mathematics was first tested for 11-yearolds in the new national mathematics tests of 2016 (a year after the project ended). Because the standards demanded of 11 year-olds by the new tests were those previously expected of a typical 13 year old, the only constant that Camden results could be compared with was the national average result for England. (The Camden average was above the national before and after the project). Importantly, the results of the primary schools in Camden that had not participated in the project were at a higher point than those of the schools in the project at its outset in 2013 (so the schools involved in the project were those with initially lower mathematics attainment scores than others in the district). The scores of these participating schools rose against the national average between 2013 and 2016, opening up a four percentage-point overall improvement for project schools. In contrast, by 2016 the attainment of district schools not involved in the project had actually fallen against the national average by two percentage-points. These qualitative and quantitative data suggest that the teachers themselves had been developing their own practices in response to their LS learning experiences in ways that subsequently improved the learning of their pupils.

We will now turn our attention to what was found about these teachers' learning processes 
from specific research into the LS group planning and post lesson discussions.

\section{Researching teacher learning in LS in the context of curriculum innovation and development}

Within the wider context of adaptations of LS to the UK context reported above, the remainder of this chapter reports on outcomes of the University of Cambridge team's research undertaken within this two-year research and development project. The team analysed teachers' LS planning discussions and post-lesson discussions in order to:

i) understand how and why LS discussions ${ }^{5}$ may impact upon teacher learning patterns and processes;

ii) identify more or less powerful components of these discussions;

iii) understand the contribution of pupil voice in LS discussions, relating this to subsequent mathematics teaching intentions;

iv) consider the longitudinal development of mathematics teacher identity in relation to LS.

In addition to these foci of analysis, the research team also sought to contribute to theory development in understanding and improving teacher learning in the context of educational innovation. Methodologically, it was our intention to contribute to the field though the development of analysis tools for the categorisation of dialogue within LS discussions, and a reliable coding scheme incorporating teacher learning. Here we draw on all elements of the research, both theoretical and methodological, to provide an overview of our findings.

The importance of professional communities of mathematics teachers was central to the research and development endeavour, since creating and sustaining such communities can be one of the most effective mechanisms for enhancing professional learning and sustained professional development (Lieberman and Miller 2008; McLaughlin and Talbert 2006; Stole et al. 2006; Webster-Wright 2009). Indeed, schools with strong teacher communities seem to have higher student achievement (Horn \& Kane 2015; Bryk, 2010). To uncover the mechanisms of teacher learning in communities that are inspired and sustained by a shared

\footnotetext{
${ }^{5}$ In the remainder of the chapter, the term 'LS discussions' refers specifically to teacher planning and discussions conducted in
} relation to LS research lessons. 
interest in LS in mathematics teaching and learning, we focused our research on the role of dialogue and its influence on learning in LS discussions. In so doing, we considered the intersections of three different theoretical perspectives for our study (Figure 6).

Figure 6. Considering the intersections of three theoretical perspectives

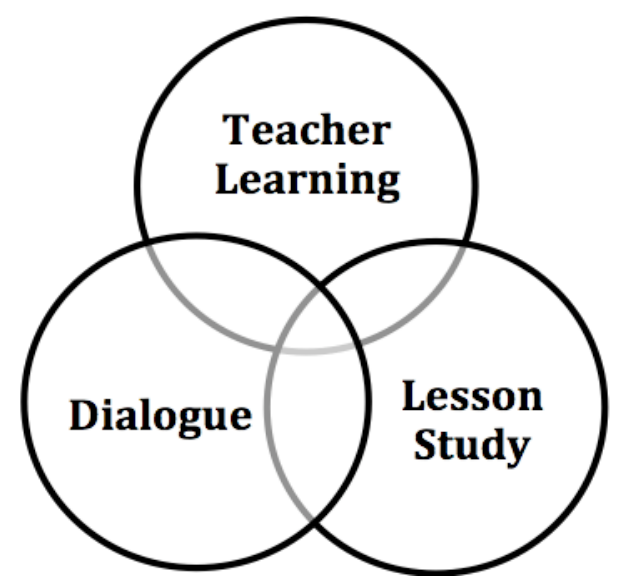

Here, it is useful to briefly review how we understand teacher learning and dialogue as concepts informing the research ${ }^{6}$.

\section{Teacher Learning in the context of LS discussions}

There is a pre-existing line of research that considers the structure or form of professional development programmes and the impact of this on outcomes, both for teachers and for students such as Desimone's (2009) linear, intervention-outcome model of teacher learning. Such models conceptualize teacher learning as features of interventions leading to teacher learning outcomes (i.e. knowledge, skills, attitudes), which can then lead to changes in teacher behaviour in the classroom. Others (Clarke and Hollingsworth, 2002) have suggested a nonlinear more idiosyncratic teacher learning model involving interconnected change sequences and growth networks. Others still have explored effects of classroom complexity (Opfer and Pedder, 2002) or cross-institutional models (Kazemi and Hubbard (2008) on teacher learning.

\footnotetext{
${ }^{6}$ We do not review LS here, given the overall focus of this volume and the fact that LS in the UK context has already been considered in this chapter.
} 
In many studies the intention is not necessarily to explore teacher learning processes or patterns, although interesting insights often arise though analysis of outcomes. Borko et al. (2012) intentionally focused on exploring teacher learning processes occurring in the 'black box' between stimulus (intervention) and response (learning outcomes) (Vermunt 2013). Our research fits within this latter frame, although the form provided through the recursive, reflexive nature of RLS is clearly the enabling context.

In considering the exploration of teacher learning through LS, the field of student learning is potentially of interest. For example, Marton and Säljö (1984) identified two distinct learning approaches that students tend to adopt in the context of their normal studies: a deep approach and a surface approach. A deep approach is characterised by the student's intention to understand, whilst a surface approach is characterised by the student's intention to remember the learning material. Others have built on these findings by elaborating and extending their conceptualisations. Vermunt and Vermetten (2004), used the term 'learning pattern' as an encompassing concept in which the cognitive processing of subject matter, the metacognitive regulation of learning, conceptions of learning and learning orientations are united. In a series of studies with university students they consistently found four such learning patterns: undirected, reproduction directed, meaning directed and application directed. Further work (Bakkenes et al. 2010), this time with teachers, revealed six categories of learning activities, building our understanding of the complexity of professional learning. The four most frequently occurring categories were: i) experimenting; ii) considering one's own practice; iii) getting ideas from others; and iv) experiencing 'friction'. Subsequent work of Vermunt and Endedijk (2011) considering patterns in teacher learning, inspired us to view LS as a 'contextual factor' that may lead to the creation of positive learning patterns and processes resulting in teacher learning. We therefore broadened Vermunt and Endedijk's model of teacher learning in the context of LS (Figure 7).

\section{Figure 7: A model of teacher learning in the context of lesson study}




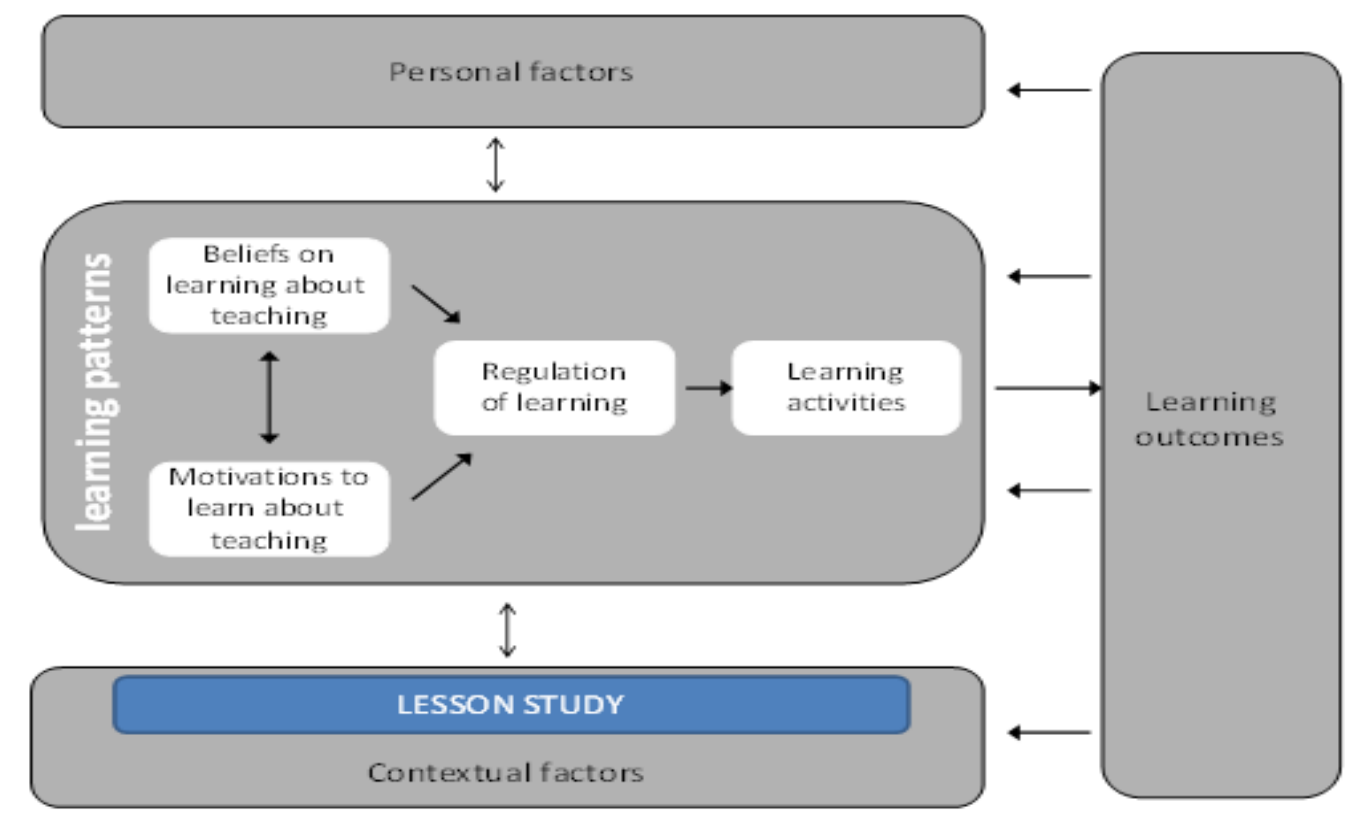

We were interested to see to how the content and character of LS discussions influenced the what and how of teacher learning; hence our interest in the next element of our intersecting theoretical perspectives - dialogue.

\section{Dialogue in the context of $L S$ discussions}

A focus on dialogue reflected our wish to understand the processes by which teachers exchange information and build professional knowledge in collaborative groups. In everyday use, dialogue means talking together. But within the sociocultural framework of understanding that underpinned our work (Vygotsky 1962, 1978; Bakhtin 1981), dialogue refers to 'any kind of human sense-making, semiotic practice, interaction, thinking and communication, as long as these phenomena are 'dialogically' (or 'dialogistically') understood' (Linell 2009, p. 990). Dialogue can be thought of as a very specific kind of talk, designed to enable people to come to an understanding of one another's knowledge and perspectives through 'interthinking' (Mercer 2000).

Collaborative interaction is intimately bound with talk, and research into collaborative working, in professional and educational contexts, suggests that 'groups seem to achieve some of the best, and some of the worst, outcomes' (Littleton and Mercer 2013, p. 24). The quality of communication within a group can provide a clue as to why some groups achieve productive 
outcomes whilst others flounder. It seems that group discussion is far from reliable in generating positive outcomes, since the implicit social norms of discussion in some groups may be used to strictly control how knowledge exchange, knowledge building, and particularly dissent around ideas, are handled (Mercer 2000; Littleton and Mercer 2013). Labelled 'groupthink' (Esser 1998; Hart 1994; Janis 1982), this phenomenon has been blamed for some catastrophic political decisions.

In contrast, professional groups that regularly produce good solutions to problems seem to do so because of 'ground rules' that generate positive conditions for interaction and knowledge building through dialogue; they seem to act in what 'may be imagined as a socially distributed cognitive process' (Måseide 2003, p.363). The talk and interaction in such professional groups mirrors that found in the research on effective group interaction amongst school students (Mercer and Littleton 2007). From this, it seems that both the features of group dialogue, and the environment that enables such dialogue, are of crucial importance.

In our work on LS in mathematics, we focused explicitly on how shared information about student performance can act as a mediating artefact for the development of common knowledge amongst teachers (Edwards 2012; Edwards and Mercer 1987; Engstrom 2003). We were interested in the teacher learning processes evident in the LS discussions and the professional learning outcomes arising, evident as developed pedagogic intentions that arise from teachers using 'knowledge that combines knowing about students and knowing about mathematics' (Ball, Thames \& Phelps 2008, p. 401). And we were further interested in the learning patterns that might be apparent as teachers engaged in sequence of LS research lessons.

Taking our extended model from Vermunt and Endedijk (2011) one stage further, we hypothesised that one or more perspectives in LS discussions may be held in tension as a 'dialogic space' is created in which teachers can 'engage with each other and, in a sense, learn to see the task [of understanding students' mathematical learning] through each other's eyes' (Wegerif 2007, p. 4). This idea of 'thinking ... in dialogues' (Wegerif 2007, p. 116) seems highly pertinent in the context of LS discussions, and is presented in Figure 8. 


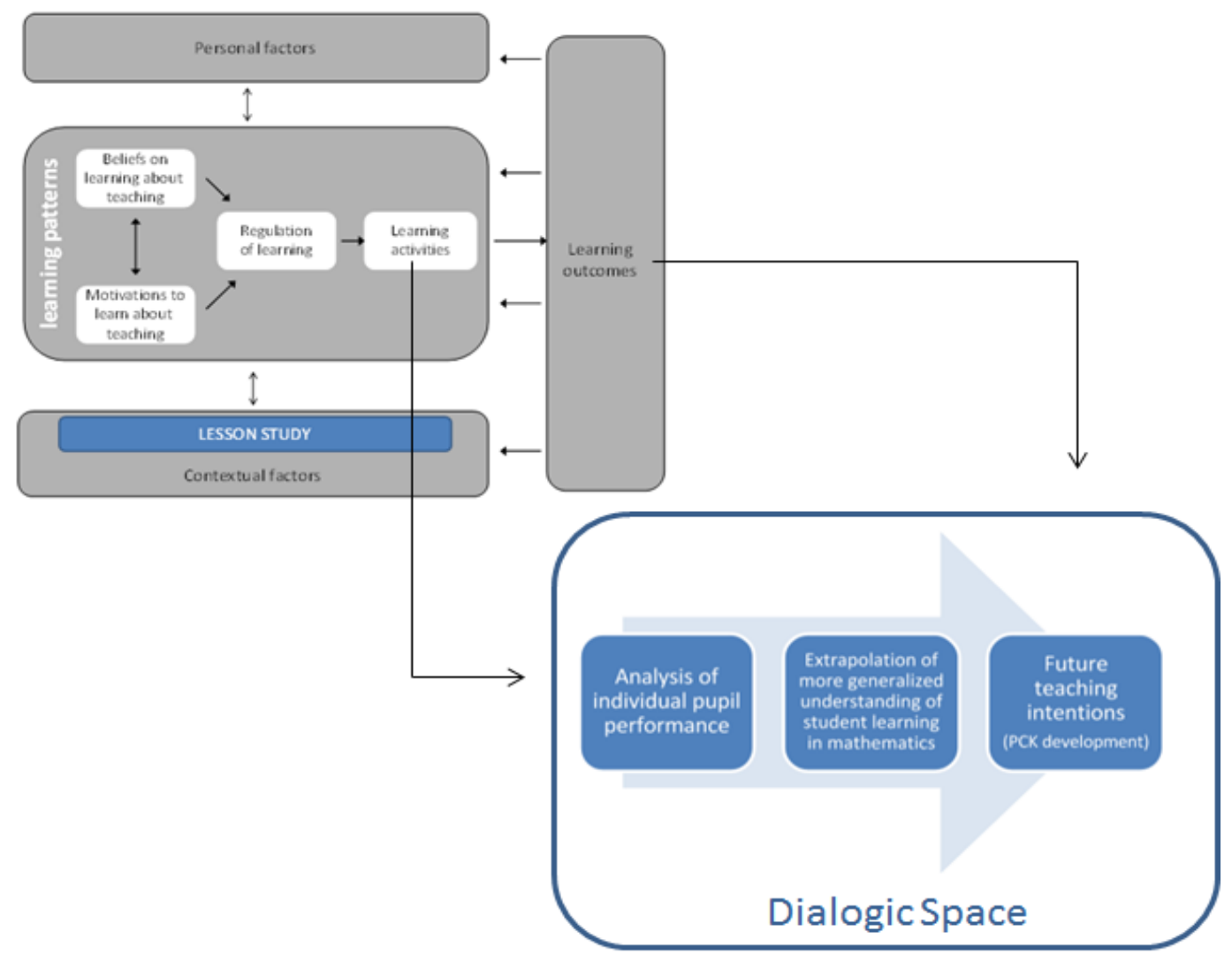

\section{Data collection and analysis approaches}

As stated in section 2 above, in district and school meetings teachers: collaboratively considered the curricular context and aims of the research lessons, selected three case students; and created detailed research lesson plans. Students were then interviewed after the research lessons were implemented. In the post lesson discussions that followed, teachers reflected on the research lesson by evaluating the progress of each case student in relation to the predetermined success criteria and considering the interview data, ultimately evaluating the teaching in relation to student learning, and considering what aspects of their teaching could be adjusted to improve the progress of specific students, groups and the class as a whole.

Data for the research element of this project came from three main sources:

1) Video-recordings of the LS planning and reflective sessions conducted in each school, roughly ranging from 20 minutes to 1 hour in terms of length. The video data were 
accompanied by LS workbooks to assist teacher discussions; these had been completed by the teachers during their LS meetings.

2) Survey data, collected at three different time points during the project to examine teacher learning over time.

3) Pupil interview data.

Several approaches were taken in the analysis of the data, in line with research question foci of the various research strands we explored. In considering the video data we developed an initial coding protocol, building on studies that detail the use of digital video as a central tool in capturing the complexity of teaching and learning processes (Powell et al. 2003; Sorenson 2006). The protocol was comprised of three sections, with features arrived at through methods associated with Sociocultural Discourse Analysis (SDCA) (Mercer, 2004; Mercer et al. 2004). This focuses on 'the use of language as a social mode of thinking - a tool for teaching-andlearning, constructing knowledge, creating joint understanding and tackling problems collaboratively' (p. 137). After building and testing the protocol through the re-visiting of numerous video-recordings of different LS discussions, the version of the protocol used for the initial analysis undertaken was eventually agreed. This consisted of three major categories: 1) Discourse-related Features detailed important elements of talk that contributed to a collaborative and productive learning environment; 2) Content-related Features pointed to teachers' mental processes in relation to specific content; and 3) Learning Points identified types of teacher learning from LS discussions, with direct reference to teaching mathematics, understanding students' learning and learning about the subject of mathematics. At this stage particular emphasis was given to dialogic moves that could be seen to reliably influence teacher learning processes - termed Descriptive Learning Processes (DLP) and Interpretative Learning Processes (ILP) - in LS professional groups in the project (Warwick et al. 2016). These terms are explained more fully in the next section.

Further analysis of the data (Vrikki et al. 2017) focused again on protocol development, with further emphasis on the reliability of coding items. The revised protocol was then used to examine the interrelationships between teacher learning and dialogue, and between differing teacher learning processes. Thus, the relationships between DLP and ILP were examined at group and individual level, and their relationship with dialogue moves was re-examined in light of the revised protocol. 
Parallel work (Vermunt et al. 2017) examined the role of dialogue in teacher learning and identity formation within the LS groups. Here, and in other work (Vermunt et al. 2015), patterns in teacher learning were the focus, rather than teacher learning processes. Using the project survey data, links between learning patterns and three identified types of teacher identity (Beijaard et al. 2004) were explored and developed in the context of mathematics teaching and learning.

Finally, transcriptions of teachers' reflective LS discussions were analysed to discover the extent to which and how pupil voice data was used by teachers within their post-lesson discussions generally, and for articulating intentions for future action in particular (Warwick et al. 2018, in press). The focus once again was on the relationship between teacher learning processes and evidence, with the evidence in question being RLS student interview data and what students had said during lessons (as reported by the teachers).

\section{Findings from the research}

Here, we present some broad findings from the various lines of research undertaken for the project. We do not attempt to provide detail of the methodological complexity of the various forms of analysis undertaken for this work; this detail can be found in the papers associated with the project, which are detailed above. Rather we hope to give a 'flavour' of the findings, illustrating their complexity and throwing light on the variables in play in professional development and teacher learning in the context of LS. We have presented this work by noting the findings of each study in turn.

\section{Study 1: Features of teacher talk promoting teacher learning}

In an initial detailed consideration of the video data (Warwick et al. 2016), we were concerned to examine what in the structure and content of the teacher talk, seemed to drive the learning conversation forward. We were interested initially in lesson studies in terms three and six where secondary and primary teachers worked together. Nine episodes from post-lesson, teacher discussions were subject to analysis. We identified as significant for teacher learning, those parts of the dialogue that began with an analysis of student learning strategies (or, in some cases, outcomes) and concluded with agreement on future pedagogical intentions. Whilst it is true to say that these episodes formed only a small part of the total content of the teachers' discussions, they were highly significant in moving pedagogic thinking forward. 
Where the discussions were more dialogic in character, teachers tended to encourage coconstruction of understanding within the group by requesting information, giving reasons, providing evidence, making supportive comments and articulating shared ideas. Less dialogic discussions in which some might take a dominant role preventing others from expressing their own perspectives or feeling a part of a collective solution were not identified as driving learning forward. What seemed most significant in our analysis was the power of particular 'dialogue moves' in effecting progress in the dialogue. Questioning (including negotiating meaning); building on each other's ideas; coming to some agreement; and providing evidence or reasoning and challenging; seemed to be dialogue moves that drove forward productive professional discussion.

In addition, two levels of dialogic features were found in the data; we called these 'dialogic moves' and 'supportive moves'. Dialogic moves are accepted within groups because they were accompanied by supportive interactional cues that seem crucial for the creation of a supportive dialogic space - a space of "reciprocity, mutuality (allowing) the continual (re)negotiation of meaning" (Mercer and Littleton 2007, p. 25). It is specifically the interaction of the dialogic moves and the supportive moves that seem to create a productive learning environment. It is also worth noting that links between vocabulary and conceptual understanding were a strong focus of the teacher LS dialogues. This is hardly surprising, given that "[mathematical] language is crucial to reasoning - to the construction of mathematical knowledge - for it provides the medium in which claims are developed, made and justified" (Ball and Bass 2000, p. 205).

\section{Study 2: Relationships between DLP, ILP and teacher learning}

Further analysis of the data (Vrikki 2017) led to radical revisions in our protocol for data analysis. Working with data from two of the project phases, we were concerned to produce a valid and reliable protocol that other researchers might be able to adopt in analysing their own work. As a result of rigorous analysis of the data, the protocol was reduced from 54 codes to seven (See Figure 9). 
Figure 9: The final, reliable version of the coding protocol

\begin{tabular}{|lll|}
\hline \multicolumn{1}{|c}{ DIALOGIC MOVES } & \multicolumn{1}{c|}{$\begin{array}{c}\text { SCOPE OF } \\
\text { DISCUSSION }\end{array}$} & \multicolumn{1}{c|}{$\begin{array}{c}\text { LEARNING } \\
\text { PROCESSES }\end{array}$} \\
\hline $\begin{array}{l}\text { [DM1] Requesting } \\
\text { information, opinion or } \\
\text { clarification }\end{array}$ & [S1] Groups of pupils & $\begin{array}{l}\text { [DLP] Descriptive } \\
\text { processes }\end{array}$ \\
[DM2] Building on ideas & [S2] Particular pupils & [ILP] Interpretative \\
processes
\end{tabular}

It will be immediately apparent that there are just three dialogue moves in this final version of the protocol which, after rigorous reliability testing, seem to be particularly significant in teacher LS discussions. This is not to say that other dialogue moves and supportive moves are not important; it is simply that requesting information, opinion or clarification; building on ideas; and providing evidence or reasoning; are those that had the strongest, most reliable association with the learning processes identified in our analysis: - Descriptive Learning Processes (DLP) and Interpretative Learning Processes (ILP). When engaged in descriptive learning processes teachers explicitly co-construct knowledge at the level of representing what is known. 'What is known' can include information from lessons plans or activities; expectations agreed for students and teaching; observations of student learning and teaching; and information gathered from the students, such as interview data. Interpretative learning processes take place when teachers attempt to go beyond what is given, unpicking this information by, for example, evaluating teaching, evaluating student learning, diagnosing student errors and misconceptions, and drawing on insights from teaching experience to consider the 'next steps' for individuals or groups. This distinction between types of learning was inspired by literature on students' learning, where different learning processes, such as deep and surface learning, have been proposed. It should be stressed here that there is no 
parallel between the deep-surface-dichotomy used in considering student learning (Marton and Säljö 1984), and our descriptive-interpretative dichotomy. Unlike deep and surface learning, there is no evidence that either descriptive or interpretive learning is more or less important than the other.

Multilevel modelling revealed a range of complex findings, revealing differential predictors of these two learning processes. When a LS group engaged collectively in DLP, in building on one another's ideas and in talking about individual students, then individual teachers showed evidence of Descriptive Learning. When individual teachers engaged in reasoning to provide support for their statements, they are also likely to show evidence of Descriptive Learning. However, when a LS group engages collectively in ILP, and focuses on groups of students, then individual teachers show evidence of Interpretative Learning.

\section{Study 3: Learning processes and development of learning patterns and professional identity}

Here we approached the data from a slightly different perspective, using survey data to analyse changes in teacher learning patterns over time. Whilst teacher learning processes affect the establishment of learning patterns and identity, the interweaving of developing learning patterns and professional identity formation was our concern. Being dynamic, identity constantly shifts according to the influence of internal and external factors; as Danielsson and Warwick (2015 p. 73) put it, 'identity is a constant becoming'. We adopted Beijaard et al.'s (2000) conceptualisation of three forms of professional identity - pedagogical expertise (related to student development), didactic expertise (related to teaching) and subject knowledge expertise.

Our analysis revealed three types of learning pattern: meaning oriented, application oriented and problematic.

'Meaning-oriented learning was characterised by learning activities such ... trying to understand how students learn, and reflecting on one's own teaching practices.... Application-oriented learning was typified by wanting to know which teaching methods work... and learning best when trying out new ideas in practice. Struggling with new ways of teaching, not knowing how to teach one's subject in another way than one is used to... and only wanting to learn things that can be used immediately in one's 
teaching, were some defining elements of problematic learning' (Vermunt et al. 2017, p. 148).

A longitudinal comparison showed an increase in meaning-oriented teacher learning and a decrease in problematic learning during the time the teachers worked with RLS. The learning patterns were strongly associated with the three forms of professional identity previously examined by Beijaard et al. (2000). The meaning-oriented learning pattern was significantly and strongly associated with all three of these professional identities. Application-oriented learning was also significantly, but to a somewhat lesser degree, associated with all three identities. Problematic learning showed negative but non-significant correlations with all three identities. These results, and the further detail provided elsewhere (Vermunt et al. 2017), suggest a significant positive correlation between what might be termed 'good quality learning patterns' - namely meaning-oriented learning and application-oriented learning - and all three identity variables. Finally, examination of the data suggested that dialogue in collaborative professional groups plays a significant role in teacher identity formation.

\section{Study 4. Student perspectives and teacher learning in RLS}

In the final study reported here, we considered the place of 'pupil voice' in the reflective LS discussions of the teachers. Here (Warwick et al. 2018, in press), we were concerned with the ways in which teachers incorporated the views of students into their post-lesson discussions, either through remembering what they had said in lessons or by referring to their student interview data. We were interested in particular in whether the use of 'pupil voice data' was associated with descriptive or interpretative learning patterns, and whether it was used to inform stated intentions for subsequent research lessons. Student interviews have been a feature of UK LS RLS since its inception, so this again seemed a legitimate focus of study. In Dudley's earlier work, student views were observed to contribute perspectives and insights that more traditional approaches and measures did not replicate. There was evidence of: (i) pupil perspectives revealing interpretations and insights of which teachers had not been aware; and (ii) these perspectives then directly informing the design of subsequent research lessons and practice. Teachers overwhelmingly reported that the pupil interviews were valuable for the same reasons (Dudley, 2013).

Using data from schools that could provide a full dataset of one LS cycle, including videorecordings of pupil interviews, we show that teachers used both descriptive learning processes 
and interpretative learning processes in integrating student interview data into their discussions. 12 episodes featured 15 instances of a direct link being made between the reporting category in our coding, representing teachers' descriptive learning processes, and the interpreting category in our coding, representing teachers' interpretative learning processes, as evidenced in the interpretation of observations and student interview responses, broader lesson evaluation and resultant lesson planning. Two episodes featured a 'jump' to interpretative learning without evidence of prior descriptive learning in the teacher discussions, presumably because the teacher speaking does not feel a need to report before interpreting. Four episodes showed evidence of descriptive learning without subsequent interpretative learning. Interestingly, all four of these latter instances led directly to wider lesson evaluation and/or the linking of this learning to subsequent planning. This adds strength to the assertion by Vrikki et al. (2017) that, whilst descriptive learning processes may influence interpretative learning processes, they should be seen as of equivalent value to the professional learner.

\section{Looking Forward}

The unusual blend of school and district level lesson study work undertaken in the Camden LS project continues to develop in London. The Camden Primary Teaching School Alliance has developed a popular LS based approach called 'Connecting Classrooms'. 'Learning hubs' have been established: - groups of schools who research at classroom, school and cluster level to develop curricular and practice-knowledge (across disciplines) for all Camden schools. A cadre of lead mathematics lesson study facilitators is enabling two additional London areas to continue with their LS practice as 'London Subject Knowledge hubs' https://www.london.gov.uk/what-we-do/education-and-youth/improving-standards-schoolsand-teaching/subject-knowledge-hubs-2. These are largely funded and operated by groups of schools and their popularity suggests that the school-district-school blend and the RLS model used in this project are considered effective enough for schools to self-sustain this work over a period of years, even at a time of falling budgets. Further work however needs to be carried out to establish not only a link between teacher learning, LS and improved student learning (described in the studies above), but also between sustained LS and sustained student and school outcomes in England.

\section{References}


Bakhtin, M. M. (1981). The dialogic imagination: Four essays. M. Holquist (Ed). Austin \& London: University of Texas Press

Bakkenes, I., Vermunt, J.D., \& Wubbels, T. (2010). Teacher learning in the context of educational innovation: Learning activities and learning outcomes of experienced teachers. Learning and Instruction, 20(6), 533-548.

Ball, D. L., \& Bass, H. (2000). Making believe: The collective construction of public mathematical knowledge in the elementary classroom. In D. Phillips (Ed.), Yearbook of the National Society for the Study of Education, Constructivism in Education, (pp. 193224). Chicago: University of Chicago Press.

Ball, D. L., Thames, M. H., \& Phelps, G. (2008). Content knowledge for teaching: what Makes It Special? Journal of Teacher Education, 59(5), 389-407.

Ball, S. (2003) The teacher's soul and the terrors of performativity, Journal of Educational Policy 18(2): 215-228

Beijaard, D., Meijer, P.C. \& Verloop, N. (2004). Reconsidering research on teachers' professional identity. Teaching and Teacher Education, 20, 107-128.

Beijaard, D., Verloop, N. \& Vermunt, J.D. (2000). Teachers' perceptions of professional identity: An exploratory study from a personal knowledge perspective. Teaching and Teacher Education, 16, 749-764.

Bjuland, R., \& Helgevold, N. (2018). Dialogic processes that enable student teachers' learning about pupil learning in mentoring conversations in a Lesson Study field practice. Teaching and Teacher Education, 70, 246-254.

Borko, H., Jacobs, J., \& Koellner, K. (2010). Contemporary approaches to teacher professional development. In E. Baker, B. McGaw \& P. Peterson (Eds.), International Encyclopaedia of Education (part 7, 3rd ed., pp. 548-555). Oxford: Elsevier Scientific Publishers.

Brown, S., \& McIntyre, D. (1993). Making sense of teaching. Buckingham: Open University Press.

Bryk, A. S., Sebring, P. B., Allensworth, E., Luppescu, S., \& Easton, J. Q. (2010). Organizing schools for improvement: lessons from Chicago. Chicago, IL: University of Chicago Press. 
Clarke, D., and Hollingsworth, H. (2002) Elaborating a model of teacher professional growth. Teaching and Teacher Education, 18(8), 947-967

Cordingley, P., Bell, M., Rundell, B., Evans, D., \& Curtis, A. (2004). How do collaborative and sustained CPD and sustained but not collaborative CPD affect teaching and learning? London: EPPI-Centre, Institute of Education.

Danielsson, A. \& Warwick, P. (2015). Identity and discourse: Gee's discourse analysis as a way of approaching the constitution of primary science teacher identities. In L. Avraamidou \& W.M. Roth (Eds.). Studying Science Teacher Identity: Theoretical Perspectives, Methodological Approaches and Empirical Findings. (pp. 71-88) Rotterdam: Sense Publishers.

Department for Children, Schools and Families. (2008). Improving practice and progression through lesson study: a handbook for headteachers, leading teachers and subject leaders. London: DCSF.

Department for Education. (2010). The importance of teaching: the schools White Paper 2010. London: DfE.

Department for Education and Science (1988). Education reform act. Retrieved from http://www.legislation.gov.uk/ukpga/1988/40/contents

Department for Education and Skills (1997). Excellence in Schools. London. HMSO

Desimone, L.M. (2009). Improving impact studies of teachers' professional development: toward better conceptualizations and measures. Educational Researcher, 38(3), 181-99.

Department for Education (2013). The national curriculum for England to be taught in all local-authority-maintained schools. Retrieved from https://www.gov.uk/government/collections/national-curriculum

Dudley, (2005). Getting started with Research Lesson Study. Nottingham, National College for School Leadership.

Dudley, P. (2008). Improving practice and progression through lesson study: a handbook for headteachers, leading teachers and subject leaders. London: DCSF.

Dudley, P. (2011) Lesson Study development in England: from school networks to national policy. International Journal for Lesson and Learning Studies, Vol. 1 Issue: 1, 85 100. 
Dudley, P. (2013). Teacher learning in Lesson Study: What interaction-level discourse analysis revealed about how teachers utilised imagination, tacit knowledge of teaching and fresh evidence of students learning, to develop practice knowledge and so enhance their students' learning. Teaching and Teacher Education, 34, 107-121.

Earl, L., Fullan, M., Leithwood, K., Watson, N., Jantzi, D., Levin, B., \& Torrance, N. (2003). Watching and learning 3: Final report of the external evaluation of England's National Literacy and Numeracy Strategies. Toronto: Ontario Institute for Studies in Education.

Edwards, A. (2012). The role of common knowledge in achieving collaboration across practices. Learning, Culture and Social Interaction. 1(1), 22-32.

Edwards, D., \& Mercer, N. (1987). Common knowledge: the development of understanding. London: Methuen.

Elliott, J. (1991). Action research for educational change. Buckingham: Open University Press.

Engström, Y. (1999). Activity theory and individual and social transformation. In Y. Engström, R. Miettinen \& R.L. Punamaki (Eds.), Perspectives on Activity Theory. Cambridge, UK: Cambridge University Press.

Eraut, M. (1994). Developing professional knowledge and competence. London: Falmer Press.

Esser, J.K. (1998) Alive and well after 25 years: a review of groupthink research. Organisational Behaviour and Human Decision Processes, 73, 2-3, 116-141.

Hadfield, M., Jopling, M., \& Emira, M. (2011). Evaluation of the National Strategies' Primary Leading Teachers Programme. London, Department for Education.

Hargreaves, D. (1999). The knowledge creating school. British Journal of Education Studies, $47(2), 122-144$.

Hart, P. (1994) Government: a study of small groups and policy failure. Baltimore MD: The Johns Hopkins University Press.

Horn, I.S. \& Kane, B.D. (2015). Opportunities for professional learning in mathematics teacher workgroup conversations: Relationships to instructional expertise. The Journal of the Learning Sciences, 24(3), 1-46. 
James, M.; McCormick, R., Black, P., Carmichael, P., Drummond, M. J., Fox, A., MacBeath, J., Marshall, B., Pedder, D., Proctor, R.; Swaffield, S., Swann, J. and Wiliam, D. (2007). Improving learning how to learn: Classrooms, schools and networks. TLRP Improving Learning Series. London. Routledge.

Janis, I. (1982) Groupthink: psychological studies of policy decisions and fiascos, $2^{\text {nd }}$. Ed. New York: Houghton Mifflin.

Kazemi, E., \& Hubbard, A. (2008). New directions for the design of professional development: attending to the coevolution of teachers' participation across contexts. Journal of Teacher Education, 59(5), 428-441.

Kuno, H. (2015) Evolving the curriculum through lesson study, in P. Dudley (Ed.) Lesson Study: Professional Learning for our time. London: Routledge. pp. 104-117.

Lave, J., \& Wenger, E. (1991). Situated learning: legitimate peripheral participation. Cambridge: Cambridge University Press.

Lewis, C. (1998). A lesson is like a swiftly flowing river: how research lessons improve Japanese education. American Educator, (Winter), 12-17 \& 50 - 51.

Lewis, C. (2016) What learning occurs at each stage of the lesson study process. Presentation given at the World Association of Lesson Studies Annual Conference, $3^{\text {rd }}$ September 2016, University of Exeter.

Lieberman, A., \& Miller, L. (2008). Teacher in Professional Communities. New York: Teachers College Press.

Linell, P. (2009). Rethinking language, mind, and world dialogically: interactional and contextual theories of human sense-making. Charlotte, NC: Information Age Publishing.

Littleton, K., \& Mercer, N. (2013). Interthinking: putting talk to work. Abingdon, UK: Routledge.

Lo, M.L. (2016) You can only see what you have chosen to see: overcoming the limitations inherent in our theoretical lenses, International Journal for Lesson and Learning Studies, Vol. 5 Issue: 3, pp.170-179, https://doi.org/10.1108/IJLLS-05-2016-0011 
Marton, F., \& Säljö, R. (1984). Approaches to learning. In F. Marton, D. Hounsell, \& N. Entwistle (Eds.), The experience of learning (pp. 39-58). Edinburgh: Scottish Academic Press.

Måseide, P. (2003). Medical talk and moral order: Social interaction and collaborative clinical work. Text, 2(3), 369-403.

McKinsey (2007). How the world's best-performing school systems come out on top. London: McKinsey \& company.

McLaughlin, M. \& Talbert, J. (2006). Building school-based teacher learning communities: Professional strategies to improve student achievement. New York: Teachers College Press.

Mourshed, M., Chijioke, C., \& Barber, M. (2010). How the world's most improved school systems keep getting better. London: McKinsey and Company.

Mercer N. (1995). The guided construction of knowledge: talk amongst teachers and learners. Clevedon: Multilingual Matters.

Mercer, N. (2000). Words and minds: How we use language to think together. London: Routledge.

Mercer, N., \& Littleton, K. (2007). Dialogue and the development of children's thinking: a sociocultural approach. London: Routledge.

Mercer, N., Littleton, K., \& Wegerif, R. (2004). Methods for studying the processes of interaction and collaborative activity in computer-based educational activities. Technology, Pedagogy and Education, 13(2), 193-209.

Opfer, V. D., \& Pedder, D. (2010). Benefits, status and effectiveness of continuous professional development for teachers in England. The Curriculum Journal, 21(4), 413-431.

Postholm, M.B. (2012). Teachers' professional development: a theoretical review. Educational Research, 54(4), 405-429.

Powell, A., Francisco, J., \& Maher, C. (2003) An analytical model for studying the development of learners' mathematical ideas and reasoning using videotape data. Journal of Mathematical Behaviour, 22(4), 405-435.

Robinson, V., Hohepa, M., \& Lloyd, C. (2009). School leadership and student outcomes: 
identifying what works and why best evidence synthesis. Auckland: New Zealand Ministry of Education.

Sahlberg, P. (2015) Finnish lessons: what can the world learn from educational change in Finland? New York. College Press.

Scribner, S. (1999). Knowledge at work. In R. McCormick \& C. Paechter (Eds.), Learning and knowledge (pp. 103-111). London: Paul Chapman.

Stenhouse, L. (1981). What counts as research? British Journal of Educational Studies, 29(2), 103-113.

Sorenson, P. D., Newton, L. R., \& Harrison, C. (2006). The professional development of teachers through interaction with digital video. Paper presented at the BERA Annual Conference 2006, September 2006.

Stol, L., Bolam, R., McMahon, A., Wallace, M., \& Thomas, S. (2006). Professional learning communities: A review of the literature. Journal of Educational Change, 7(4), 221-258.

Takahashi, A., McDougal, T. (2016) Collaborative Lesson Research: maximising the impact of lesson study. ZDM Mathematics Education. 48(4), 513-526

Van Veen, K., Zwart, R. \& Meirink, J. (2012). What makes teacher professional development effective? A literature review. In M. Kooy \& K. van Veen (Eds.), Teacher Learning that Matters: International Perspectives (pp. 3-21). New York: Routledge.

Vermunt, J. D. (2013, 22 May). Teacher learning and student learning: are they related? Inaugural lecture given at the University of Cambridge, Faculty of Education.

Vermunt, J.D., \& Endedijk, M.D. (2011). Patterns in teacher learning in different phases of the professional career. Learning and Individual Differences, 21(3), 294-302.

Vermunt, J. D., \& Vermetten, Y. J. (2004). Patterns in student learning: relationships between learning strategies, conceptions of learning, and learning orientations. Educational Psychology Review, 16(4), 359-384.

Vermunt, J.D., Vrikki, M., Mercer, N. \& Warwick, P. (2015). UK teachers' perceptions of Lesson Study and its effects on teacher learning: a survey study. Paper presented at the 16th Conference of the European Association of Research on Learning and Instruction, Limassol, Cyprus. 
Vermunt, J.D., Vrikki, M., Warwick, P., \& Mercer, N. (2017). Connecting teacher identity formation to patterns in teacher learning. In D.J. Clandinin \& J. Husu (Eds.), The SAGE handbook of research on teacher education (pp. 143-159). London: SAGE.

Vrikki, M., Warwick, P., Vermunt, J.D., Mercer, N., \& Van Halem, N. (2017). Teacher learning in the context of Lesson Study: A video-based analysis of teacher discussions. Teaching and Teacher Education, 61, 211-224.

Vygotsky, L. (1962). Thought and language. Cambridge MA: MIT.

Vygotsky, L.S. (1978). Mind in Society: the development of higher psychological processes. Cambridge, MA: Harvard University Press.

Warwick, P., Vrikki, M., Vermunt, J.D., Mercer, N. \& Van Halem, N. (2016). Connecting observations of student and teacher learning: An examination of dialogic processes in Lesson Study discussions in mathematics. ZDM Mathematics Education, 48, 555-569.

Warwick, P., Vrikki, M., Færøyvik Karlsen, A-M., Dudley P. \& Vermunt, J.D. (2018) 'Instead of numbers, I would make it decimals': the role of pupil voice in teacher learning in Lesson Study. Under review.

Wegerif, R. (2007). Dialogic education and technology: expanding the space for learning. New York: Springer.

Webster-Wright, A. (2009). Reframing professional development through understanding authentic professional learning. Review of educational research, 79(2), 702-739.

Ylonen, A., Dudley, P. and Lang, J. (2015) London Schools Excellence Fund New Curriculum Higher Order Mathematics Lesson Study Programme Final Report, Greater London Authority, London.

Yoshida, M. (2002). Lesson study: an introduction. Global Education Resources, NJ. 
